\title{
CONTROL AND DYNAMICS
}

\section{PERFORMANCE OF A SODIUM}

COOLED REACTOR POWER SYSTEM. 


\section{DISCLAIMER}

This report was prepared as an account of work sponsored by an agency of the United States Government. Neither the United States Government nor any agency Thereof, nor any of their employees, makes any warranty, express or implied, or assumes any legal liability or responsibility for the accuracy, completeness, or usefulness of any information, apparatus, product, or process disclosed, or represents that its use would not infringe privately owned rights. Reference herein to any specific commercial product, process, or service by trade name, trademark, manufacturer, or otherwise does not necessarily constitute or imply its endorsement, recommendation, or favoring by the United States Government or any agency thereof. The views and opinions of authors expressed herein do not necessarily state or reflect those of the United States Government or any agency thereof. 


\section{DISCLAIMER}

Portions of this document may be illegible in electronic image products. Images are produced from the best available original document. 



\title{
CONTROL AND DYNAMICS \\ PERFORMANCE OF A SODIUM \\ COOLED REACTOR POWER SYSTEM
}

\author{
Submitted to \\ UNITED STATES ATOMIC ENERGY COMMISSION \\ Chicago Operation Office \\ P.O. Box 59, Lemont, Illinois \\ Contract No. AT(11-1)-666
}

ALCO PRODUCTS, INCORPORATED

Research and Development

Schenectady, New York 
- 


\section{Introduction}

\subsection{Objectives and Method of Approach}

High plant efficiencies can be realized without excessively high core temperatures and high coolant pressures by the use of a liquid metal coolant. In an attempt to prove the feasibility of liquid sodium as a reactor coolant, ALCO Products, Inc., under the sponsorship of the Atomic Energy Commission $_{8}$ is undertaking a design study of three vital system components: the intermediate exchanger, the boiler, and the superheater. Since, in the past programs, the nuclear reactor had been the major focus of attention, the development of the sodium cooled reactor and sodium pumps for this application are thought to need less development than the heat exchanger equipment. Consequently, parallel design studies of the reactor, pumps, and other system components have not yet been initiated.

The static and dynamic behavior of the heat exchange equipment depend to some extent on the behavior of the other system components. (See Fig. 1) Therefore, static and dynamic models of these other components must be formulated in order to account for their interactions. However, since the behavior of these as yet unspecified components is not of central interest in this study, crude models have been formulated without committment to any specific hardware design. More articulate models for the heat exchangers and those elements limiting controllability have been formulated.

Static and transient thermal stresses as well as a high steam pressure and temperature make difficult the structural design of the sodium heated boiler and superheater. The greatest structural problem appears to be associated with the superheater tube sheets, thick slabs of metal supporting the superheater tubes and separating the steam from the sodium. Rapid and large changes in fluid temperature coupled with the slow ther mal diffusion time through the metal could cause significant transient thermal stress in addition to the already large static pressure, bending, and thermal stresses. Many other parts of the system could also be significantly stressed if large temperature transients occur. Hence, it is desirable to control thermodynamic states to prevent fluid temperature surges at any point in the sodium or steam loops during normal and casualty operation.

The steady-state heat exchanger design, for the most part, facilitates this kind of control. Because each of the exchangers has a high effectiveness and because the steam and sodium flows are maintained proportional to the load power, the steady-state sodium and steam temperatures do not vary appreciably with load over the entire useful load range. This investigation shows that, during transient changes in load, the steam and sodium systems ${ }^{\circ}$ temperature changes will not significantly exceed the small steady-state temperature changes, provided that the control system maintains the design 
steady-state ratio between the flow rates and power level during the transient. In order to achieve this, the controlled response of both sodium flow rates to a change in power level must be made significantly faster than the longer characteristic (transport) times of the heat exchangers.

Generally, power level changes are initiated at the load end. Hence, normal control is geared for this type of disturbance. Power level changes may also be initiated at other points in the thermodynamic system. Reactor scram, sodium pump failure, or feed water pump failure would require a shut-down. Temperatures can be maintained after such a casualty disturbance provided all flow rates and the output power are maintained proportional to the transient disturbance power level. This is achieved through a bi-directional control signal propagation scheme. When an abnormal signal occurs, it propagates in both directions toward the power source (the reactor) and the power sink (the electrical load) - overriding the normal control signal (derived from the electrical load variations)

An analog computer study of the controlled system behavior for normal control is discussed in Chapter 2 and for casualty control in Chapter 3.

\subsection{Conclusions}

\subsubsection{Uncontrolled Behavior}

1.2.1.1 An accurate analog model for the complete system, valid for large disturbances, is not feasible with the size of available computers.

1.2.1.2 Large temperature and pressure swings can occur. The maximum amplitude of variation will not be significantly different from the new steady-state value following a step disturbance.

1.2. 1.3 The natural circulation loop is stable and non-oscillatory according to both analytical prediction, and the analog computer study.

\subsubsection{Controlled Behavior}

1.2.2.1 Extremely good normal control can be achieved with fixed parameter commercially available electronic controllers. Fast flow measuring instruments are required. Also reactor-control-rod motion during transients is necessary. Good control of boiler level results with measurement of level only, in spite of a large tray lag, provided, that a fast differential pres sure (level) sensor is used.

1.2.2.2 It is desirable to baffle tightly one of the argon gas blankets in either the boiler or superheater, in order that the flow through these exchangers may closely follow a transient change in secondary sodium pump flow. 
1.2.2.3 The optimum controller adjustments and system performance are relatively insensitive to parameter variations. The transient performance depends primarily on the boiler two-phase energy storage time constant. It is desirable that this time constant be large compared to the secondairy sodium loop inertia-resistance time constant. It is also desirable that one transport time (the shell side) in each exchanger be large relative to the inertia-resistance time constant of the sodium loops. In the reactor, a small sodium transport time appears to be desirable (this has not been modeled in the analog study).

1.2.2.4 Casualty bi-directional control signal propagation with override capability appears to cause successfully a power coastdown following a component failure without subjecting any part of the thermodynamic system to significant transient temperature or pressure variations. Flow rates and power level track down to the $15 \%$ power level, corresponding to the minimum controlled sodium flow rate, before allowing system temperatures to vary. With this small flow, subsequent temperature coastdown is more than six times slower than when $100 \%$ load sodium flow rates are employed. A finite minimum flow through the reactor is required to remove the decay heat.

\section{Normal Operation and Control Philosophy}

Normal operation has been defined by the steady-state design. Control shall maintain the steady-state characteristics and provide the best path between steady-state thermodynamic state points. Three control or regulation, problems exist in this design: pressure regulation, sodium-steam temperature regulation, and boiler liquid level regulation.

\section{1 Normal Operation}

The steady-state steam and sodium temperatures have been determined during the design of the $1 \mathrm{HX}$, boiler, and superheater.

The design provides nearly constant terminal temperatures for each exchanger over the entire useful load range. The Atomic Energy Commission has placed requirements on the flow and load transients that each exchanger must structurally withstand.

Normal operation and control divide into three areas which are discussed separately - pressure regulation, temperature regulation, and boiler liquid level regulation.

\subsection{The Role of Linear Theory}

The fields of linear algebra and linear differential equations have 
reached a relatively high degree of development and have proved us eful tools in many fields of physical analysis. In particular, most of the theories, tools, and practices in feedback control rely upon linear equations or representations. The most important characteristic associated with linearity is superposition; that is, any system or signal may be constructed by the linear summation or superposition of other known systems or signals.

Fortunately, many physical systems are linear or may be considered linear within some range of operation or variation. For these cases, all of the associations, techniques, and experience of linear analysis may be drafted for the problem study. If the linear model is analyzed at various load levels, comparison of the results at the various load levels indicates the degree of non-linearity involved. The effect of linearized non-linearities in closed loop studies appear as variations in time constants or loop gains. Since some non-linearities are essential, a linearizing technique may give erroneous conclusions. These non-linearities generally have discontinuous first derivatives. Linearization generally describes or formulates a function in terms of its local slope. Chordal approximations are also commonly used. For essential non-linearities, no well-defined slope exists at the discontinuity. Furthermore, the slope of the chordal approximation varies significantly with input amplitude.

In the following two sections, the modeling and analysis of the various control modes is based upon linear concepts and models. The actual nonlinear effects and/or considerations are discussed in the respective sections.

\section{3 The Cascaded Control (See Fig. 2)}

Feedback control is a means of achieving desired performance with an imperfect power modulator and with load disturbances. Within the scope of normal operation, pressure and boiler liquid level regulation provide the desired performance. The manipulated variables, primary and secondary sodium flow rate, feedwater flow rate, and reactor rod position, were selected during the steady-state design. The communication path between the regulator output and the feedback input, however, involves a number of significant time lags. These lags and the power available, limit the maximum level of controllability. Thus, a reduction in the significant lags will increase the maximum achievable controlled system performance.

The fewer dynamic lags in a control loop, the easier the control problem. The simplest element to control is a simple lag. Theoretically an infinite gain controller may be used. This may require an infinite power or torque source, however, and would therefore be unrealizable.

Feedback control permits a large change in the manipulated variable for a short period following a disturbance in order to achieve a fast speed of response. However, feedback automatically reduces the manipulated variable to the required steady-state value. If the controller does not back off fast enough, then 
the output variable will overshoot the required value. A conservative criterion for optimum performance is $5 \%$ overshoot response to a step in command input (a similar criterion is useful for disturbance inputs). This criterion provides a good speed of response without excessive overshoot or tendency to instability. A minimization of loop dynamics permits faster speeds of response. Several loops in cascade may each provide fast response and thus a faster overall response than one loop enclosing the system.

The fast speed of response is achieved by high gains. The small loop permits high gains with non-oscillatory responses. A high controller gain, however, may not be achievable because of saturation. The initial hard hit of the manipulated variable following a step input may require a disproportionately high power level with regard to steady-state requirements. This requirement should be considered in any closed loop design.

Small local loops not only provide dynamics isolation but also an insensitivity to loop parameter variations. Linearization of a non-linear relationship develops load variable coefficients; that is, the coefficients vary between operating points. System time constant variations do not affect proportional loop stability or overshoot. Furthermore, the controller gain may be high enough to mask any variations of the system gain. Hence, local loops reduce the sensitivity to variations of loop parameters. This consideration is important in the application of fixed parameter controllers.

\section{4 Local Loops}

The advantages of local loops to minimize the effects of dynamics or parameter variations have four likely applications in this system.

\subsubsection{Sodium Flow Control}

Two of the manipulated variables in this system are the primary and secondary flow rates. A detailed design of these two transport loops has not been completed. This study assumes that each sodium loop employs a variable speed centrifugal pump driven by a wound rotor induction motor.

Variable flow magnetic pumps might also be used. The dynamic behavior of he magnetic pumps may be more favorable for control, depending on the size of the magnetic flux lag and power saturation level. In any case, the analog dynamic representations are similar

Each sodium flow control manipulates armature resistance in response to the difference between the pump output flow rate and the demand flow rate. The demand flow rate is the set point of the controller.

In the secondary loop, two mass storage regions, the gas blankets in the boiler and superheater, can severely limit the performance of the secondary 
loop and therefore the overall control. All the following analysis assumes that, by tightly baffling one of the gas blankets so that transient flow through the baffle is small, only one gas blanket is effectively coupled to the sodium flow. An equivalent loop length of 150 feet and 300 feet are used for the primary and secondary sodium loops respectively.

In steady-state the energy provided by the pump equals the energy dissipated in pipe friction. During a transient however, the time integral of the difference between power in and power out to the sodium loop equals the change in the stored kinetic energy of the rotor-pump-fluid. System load decreases demand less power to the loop. The minimum however is zero power-in corresponding to infinite secondary resistance. Abnormally large load decreases such as during casualty control may demand a larger difference between power in and power out than possible through the pump manipulation to achieve the desired speed of response. Such instances require an additional means of energy dissipation or removal. Some form of dynamic braking should be provided in the system and coupled with the controller output. Several methods are available. An eddy current brake with the centrifugal pump drive is one possibility. The magnetic pump provides a simple solution in that a reversal of polarity of the pump control voltage changes the pump to a motor or energy in to an energy removal capacity over and above the normal pipe friction.

This scheme relies upon the quality of the flow instrumentation. Should difficulty arise in measuring the sodium flow rate, an alternative sensing of the sodium temperature may provide satisfactory results. Temperature measurement tends to be slow in responding to disturbances. This sluggishness, however, might be eliminated by a lead compensation network and by an anticipatory signal through measurement of steam flow rate. This scheme has not been studied on the computer. However, it is anticipated that the steam flow rate signal will require a gain proportional to the load level, since temperature variations are proportional to the percentage change (or logarithic change) in flow rate. It may prove helpful to measure pump speed and cause this to be proportional to steam flow rate (or proportional to a lead compensated steam flow rate measurement), thus again employing the cascade concept.

\subsubsection{Reactor Rod Control}

Thermal reactors generally have rods of a moderator which may be manipulated to affect the neutron population. The rod actuator is a positioning device. The inertia of the rod and actuator mechanism provides a lag between the demand and response. However, this may be controlled as first order lag and should be quite simple to speed-up within the limitations of power supply saturation.

\subsubsection{Feedwater Control}

The feedwater flow control, like the sodium flow control, has not been 
designed as yet. A conventional form of feedwater control is anticipated. Most high pressure boiler systems use a staged constant speed centrifugal pump with a flow control valve. This analog computer study incorporates such a feedwater scheme. Negligible dynamics are involved in this system, a good justification for such a scheme.

\subsubsection{Steam Turbine Governor}

Another local loop common to electric power generating stations is the turbine speed governor. The dynamics enclosed by this cascade controller are the turbine steam storage capacity and the turbine-generator rotor inertia. This cascade loop has little bearing on the normal thermodynamic control problem, for the loop is far faster than the steam-sodium system.

During normal operation, the governor manipulates power-in to match power-out. The casualty control philosophy uses the governor to adjust the power-out to match power-in; the turbine governor set point senses steam pressure rather than turbine speed.

\subsection{Pressure Control}

Two separate conditions require pressure regulation. The steam turbine design generally provides a peak operating efficiency at a specific supply pressure, the efficiency dropping with any deviation from this design supply pressure.

Also, maintenance of constant temperatures within the boiler and superheater requires constant steam pressure. The mode of control and the computer results are discussed in the following sections.

\subsubsection{Computer Model (See Fig。3)}

To handle the pressure controlproblem, one must consider the system from the turbine throttle valve back to the reactor. A manipulation of the steam valve may be considered a disturbance to the pressure control system. Turbine back-pressure does not affect the steam flow since the turbine and valve appear as a choked restriction. Also, since the controlled speed and voltage responses are much faster than the boiler response, a load change is almost immediately reflected in a valve manipulation.

A step change in valve area is a step in steam flow rate. The integral of this provides the change in boiler pressure. However, the pressure flow dependence at the steam valve provides a negative feedback path. This path provides an open loop (no pressure regulator) stabilization of the boiler pressure droop. The paths of communication reflect the change in steam generation (no sodium flow rate change) from the increase in boiler sodium to steam temperature difference. This is also a negative feedback which 
tends to stablize the pressure droop. However, the combined effects of increased steam flow rate and decrease in saturation temperature as viewed by the superheater provides a superheater outlet sodium temperature droop since more energy is extracted from the sodium. This is a destabilizing effect since less energy is available to the boiler for steam generation. The final steady-state pressure droop depends upon the combined gains in these feedback paths. Other system components affect the steam system behavior after appreciable transport time. In particular, the reactor tends to return the steam states toward their initial conditions causing some overshoot in the transient response.

\section{5.2 Closed Loop Pressure Response}

The methods of controlling sodium flow rates provide a fast or a minimum dynamic distortion path for pressure control. The question of what to measure in order to command the secondary flow controller setpoint must be answered. This mode of control must provide good pressure regulation and isolate the loop temperatures from system disturbances. The steady-state thermodynamic state points of the system maintain nearly constant terminal temperatures over the useful load range, provided the steam flow and sodium flow rates are nearly in a fixed proportion. Maintenance of these state conditions throughout a transient response would provide the best possible control.

Two separate philosophies of control provide this idealized control. The essence of regulation is to isolate the regulated variable from its disturbances. The control action should weaken the coupling between the regulated variable and the disturbances. Feed forward control can theoretically provide a complete uncoupling.

Feed forward control is a means of parallel path communication in which a corrective action along one path just "bucks out" the effects of a disturbance feeding along a natural path in the system. The bucking signal is directly initiated by the disturbance. This method of control however does not provide an actual comparison between input and output. Should some piece of equipment stray from its initial design characteristics, the system has no means of self correction.

Feedback control philosophy has inherent differences from feed forward control. The disturbance does not directly initiate a correction action. An error in the regulated variable must ensue before a corrective action can take place. This is not true if a derivative mode is provided in the controller; however, in practice this is a poor mode of control because the derivative action is sensitive to high frequency signals. Any "noise" in the sensed variable is amplified by the derivative mode. The advantage of feedback control is its self corrective capacity. Should some system parameter drift or a non-measured disturbance occur, a path of communication is available to feed back this information to the manipulated variable. 
The scheme of control in this system study uses the low distortion path of secondary flow manipulation for pressure regulation. The setpoint to the flow controller is in both a feed forward and feedback path. The pressure regulator output and the steam flow rate establish the flow controller setpoint. The steam flow sense provides a feed forward path which anticipates the disturbance to the pressure. If no distortion (lagging) occurred in the sodium control loop perfect cancellation would ensue; however, some distortion does occur which provides a pressure droop. In steady-state the ratio of steam flow to sodium flow is nearly constant. Therefore, the primary task of the pressure regulator is to "trim" the sodium flow rate to eliminate the slight pressure offset and insure proper steady-state correspondence between steam and sodium flow rates. This is the feedback path. (See Figs. 10a, 10b.)

The fact that the controller gains may be maintained constant with large load variations indicates that conventional constant parameter controllers may be employed throughout. However, if steam flow rate is not sensed, the optimum loop gain should vary inversely with the load level. The feed forward path does not change the variable optimum pressure gain requirement, but it facilitates good performance with less than optimum control adjustment.

The local loop scheme for isolating the sodium dynamics and anticipatory action of the steam feed forward control action provide the heart of the solution to the pressure regulation problem. The anticipation provided by the steam sense is in the main equivalent to the derivative mode of feedback control but without the noise sensitivity.

\section{6 Temperature Regulation}

In order to minimize transient thermal stresses, it is desirable to maintain system temperatures as nearly constant as possible. Three things have been provided in the control program to achieve this. Good pressure regulation has virtually eliminated any temperature deviations at the boiler and superheater terminals. However, the intermediate exchanger terminal temperatures may drift from a constant condition if the reactor outlet temperature changes or if an unbalance between primary and secondary flow rates occur. To eliminate the second condition, secondary flow rate provides the set point to the primary flow controller. This essentially isolates the intermediate exchanger from temperature variations.

Even though the steady-state reactor temperatures do not vary as load changes with fixed rod position, transient temperature variations may occur in response to a coolant flow rate variation. The analys is requires a scheme of compensation by which a disturbance (flow change) response (outlet temperature) may be eliminated. This compensation also reduces temperature variations within the reactor. Here again the disturbance isolation bases upon a local loop for minimum distortion and a feed forward path to "buck out" the effect of the disturbance. The transfer relationship between flow rate and reactivity is a "forgetter" function. 
The rod position in the reactor is a manipulatable variable. If the transference from rod position to outlet temperature is exactly equal and opposite to the flow transference, then a means of exact cancellation is possible. In practice however, the actuator dynamics and thermal lags provide a limitation to this correction. The local loop around the rod actuator minimizes the actuator distortion. Since the transient change in reactivity is proportional to the percentage change in flow, a variable compensation gain inversely proportional to the local flow is required. This is the only variable gain required in this control scheme. It should also take into account non-linearity in the rod stroke vs. the coolant steady-state average temperature. The non-constant gain can be realized with a diode function generator or a non-linearly wound resistor.

\subsection{Boiler Liquid Level Control}

The prime objective of liquid level regulation is insurance against liquid carry-over to the superheater or liquid starvation to the boiler tubes. A feedback loop from liquid level measurement to feedwater manipulation provides a mode of self regulation.

\subsubsection{The Dynamic Model (See Fig. 4)}

Liquid feed to the boiler tubes is by natural circulation. This liquid is supplied by the drum separator. The riser discharges to the drum separator. Feedwater supplied to the boiler enters onto the perforated deck plate and flows radially to the center. The flow on the deck plate discharges to the central downcomer which feeds into the liquid hold-up region in the separator. The perforated deck plate is a means of increasing the feedwater enthalpy up to the saturation temperature. Steam passes through the perforations, some of which condenses in the feed flow: The response of the deck plate weir liquid out-flow to liquid in-flow provides a significant lag to the feedwater system.

Another dynamic effect is in the boiler circulation. The disturbance to the liquid level problem is a change in steam generation. Since pressure regulation is good, pressure variations have negligible effect on circulation or boiler level. With an increase in steam flow, the riser out-flow increases. This increase however leads the downcomer response. This phase shift accounts for the initial surge in boiler level.

Also the phase shift provides an additional disturbance to the liquid level regulation. The drum separator is a mass capacitance with four streams feeding in or out. Feed flow is manipulated to provide a balance between inflow and out-flow as well as to correct any drifting of the liquid level and to account for blowdown. 


\subsubsection{Computer Results (See Figs.11a, 11b)}

The mode of control provided in the analog computer study utilizes a proportional plus integral controller which senses only liquid level. This is a one term controller as opposed to the typical three term controller being provided with contemporary boiler systems. The maximum deviation to a $10 \%$ step in steam valve for the load range is approximately half an inch of level. Since the one term controller provides good regulation, the three term controller would provide little improvement. However, if the valve characteristics are non-linear, it may be desirable to employ a local feedback loop to control feed flow, the set point being varied according to errors in liquid level. The only advantage to be gained from measurement of steam flow would appear to be a feed forward anticipation with constant (unity) gain which would make less than optimum level gain adjustment possible, thus increasing stability without sacrificing speed of response. This is similar to the pressure control scheme. The level upward surge following a load increase is much smaller at 2200 psi than at low pressure. Hence, the complicated delays employed by some three element controller manufacturers are unnecessary.

The good control is inherent in the static design of the drum separator. The cross-sectional area of the boiler is large enough to provide low onedimensional effective throughput velocities. Ther efore, deviations are slow to occur. The controller provides correction before the error can reach any sizeable magnitude. The effect of the deck lag is evident in the phase shift between the in and out-flows. This apparently is not sufficiently detrimental but a means of isolation may be provided by a "forgetter" transference to the level controller set point. This transference could sense the pressure drop across the deck plate. The sensitivity would be to rates of change of steam flow. Valve rate or area saturation generally limits achievable performance however.

The well known paradox in boiler liquid level control is in evidence in these traces. The initial level surge has caused the feed flow to be reduced which is contrary to what is actually needed. Boiler surge or swell is caused by a step increase in riser out-flow upon a step change in load. The downcomer inertia is sufficient to prevent instantaneous downcomer flow change. The step increase in riser out-flow is attributable to an increase in steam generation caused by flashing due to a finite rate of pressure decay and in creased heat transfer due to increased sodium flow and temperature difference. Of the three, the sodium flow change is by far the most important in this system. 


\section{Casualty Operation and Control}

The results of Chapter 2 concern normal operation. In normal operation, the system operates at the static design state points which have been predetermined as safe operating conditions. The results of the normal control analog computer study indicates that none of the transient variations deviate far from the desired steady-state values. This chapter concerns abnormal or casualty control and the possible transient and steady-state deviations from the normal state points.

\subsection{Possible Casualty Operation}

Two separate points of view may be applied to the casualty problem. One involves control and the other no control.

\subsection{No Control}

In the no-control philosophy, the system must ride-out the transient condition. This is a brute force approach and requires a "hefty" (strengthwise but not transient thermal stress-wise) design of the system equipment. With no-control, there likely would be large amplitude variations in the system states. Such variations would represent large deviations from the desired normal operating state points.

Complete modeling requires large amplitude accuracy. This may require a general non-linear system model. This model however does not require a "high" degree of frequency matching with the system for this is an open loop mode of action and the final steady-state values are of major importance.

\subsubsection{System Under Control}

The other approach to casualty problems is some mode of control action which tends to isolate the casualty. Should such a control be possible then the normal operation state points are maintained. This reduces or eliminates the possible destructive action that could occur with the open loop approach.

Computer modeling is the same as for normal operation control studies. A higher frequency matching is necessary in a closed loop study. If the control action provides a minimum deviation from the state points, then the linearized small amplitude model is satisfactory.

\subsection{Signal Propagation}

A simple but instructive visualization of the casualty problem is the pebble in the pond analogy. Consider a still pond as analogous to a system functioning under normal operation. Drop a pebble into the pond. This is a 
casualty disturbance to the system. If the system is permitted to function open loop with respect to this disturbance, then the casualty would propagate though out the system much like a wave front propagates away from the pebble. However, if some mode of action could be initiated at the point of casualty, equal and opposite in effect, then the effect of the casualty would be "bucked out" before it had an opportunity to propagate to other regions of the system. In the pebble and pond analogy, this "bucking out" would be a wave originating at the same place and time as the pebble wave and equal but opposite in amplitude. This wave propagates with the same speed as the disturbance so that a net zero amplitude disturbance is insured at all times and places.

\section{3 Control Scheme (See Figs. 5 and 6)}

In Chapter 2 various paths of control communication are developed. In each case, a local control loop is used if performance warrants. In so doing, the dynamic performance has been greatly improved. These are very fast paths of communication. In normal control, the set point dependencies of the local loop controllers are determined. For casualty control however, different set points are necessary. The scheme of control is one of selection. For each casualty considered a desired set point is determined for each controller.

The role of the selector is two-fold. It determines the existence of a casualty and then establishes the desired controller set point correspondence.

The selectors are binary intelligence units. Several schemes of selector design are possible. This design used here is a lower selection scheme. Various signals may enter the selector but the lowest signal determines the mode of control. Necessarily then, a casualty must be sensed as a low signal and during normal operation the normal modes of control must be the low valued signal to the selector.

For the casualty problem several additional communication paths have been added. These additions are discussed in connection with the specific casualty problem. The final control scheme provides fast communication between problem and response. The overall result is "bucking out" or isolation of a disturbance at its origin; thereby leaving the rest of the system at a normal operating state.

Many of the normal states however are selected at the low load level. For pressure regulation, the power to and from the boiler must be matched. Many of the casualty controls presented reverse the casuality of normal control. In the casualty control the turbine speed regulator set point tracks pressure. This provides for a reduction of load to the boiler to match the boiler incoming power.

The equipment requirements of the casualty control modes discussed are well within the capabilities of conventional off-the-shelf electronic control components . 


\section{4 Failures}

The failures and the modes of correction are discussed under their specific headings. The first three casualty conditions are problems which occur from without the sodium-steam exchange network. The latter occur within this network.

\subsubsection{Loss of Feedwater}

Should control over the feedwater be lost, then a control mode should preserve a balance between out-flow and in-flow. During normal operation, the feed flow must track the steam generation; however, in the casualty mode, the steam generation tracks the feed flow. A liquid level override signal from a lower limit provides a signal to the secondary flow controller selector which requests the sodium flow to control liquid level. Again the pressure regulation is maintained through a pressure override on the turbine governor. All other control actions function normally.

This override pressure controller gain setting and the pressure response are representative of all modes of casualty control in which the pressure override on the turbine speed governor provides pressure regulation. The regulation loop is the same for each casualty condition which selects this mode. Differences in the response occur only in the disturbances to this loop.

In the event the feed flow control is lost at a high value, then an over level sense should actuate some means of correction such as a motor operated gate valve. This could be to full closure or some intermediate point. For partial closure then the previous level casualty control will automatically take over. The advantage here is the thermodynamic states are maintained so that a slow manual shutdown, if desired, is possible.

\subsubsection{Reactor Scram}

Reactor scram calls for a complete and immediate shutdown of the energy scurce. This mode may be excited through a manual request or some one of the automatic safety provisions on the reactor may request this mode. The control rods are dropped immediately. If no other manipulation occurred such as a flow change the reactor outlet temperature would drop. A low temperature selector on the reactor outlet temperature selects this temperature as the sodium loop set point. In this case, however, it is advisable to have primary sodium flow control the reactor outlet temperature directly. A signal provision discussed under loss of sodium pumps and measurement provides a possible mode in which secondary sodium flow tracks primary flow rate. Primary flow control of reactor outlet temperature insures a minimum of temperature variation to the intermediate heat exchanger. Maintenance of balanced primary and secondary flows minimizes temperature variations from the intermediate exchanger. 
This, however, is a proposed scheme which requires detailed information about the reactor. The sodium loop becomes slower with diminishing flow rates. The effective control loop gain increases with decreasing flow, therefore, a fixed parameter controller necessarily must be adjusted for the worst system condition. This necessarily sacrifices the initial speed of response. This control mode may not prove feasible if the temperature response to rod motion is fast relative to the control loop dynamics.

To eliminate this lagging, the sodium loops could also scram. This is an open loop mode of action with respect to reactor outlet temperature and therefore nothing can be said about its variation. If the sodium flows drop faster than the rod, then an over-temperature might be possible. In any event, analysis requires a more detailed knowledge of the reactor.

\subsection{Loss of Load}

Should some casualty occur at the electrical end of the system, circuit breakers could be opened. This reflects as a near instantaneous dropping of load. The turbine governor would react immediately and shutdown the steam valve. In order to minimize the thermal energy stored in the system, it is necessary to scram the reactor immediately. Signals propagate from both ends of the system through the normal and casualty control paths and meet somewhere in the middle. To reach final steady-state, the after-heat from the reactor must be removed and the sodium and steam allowed to reach isothermal equilibrium. Minimum bounds on the sodium flow rates enable energy to be transported from the reactor to the boiler. A pressure relief valve may be set to maintain some maximum steam pressure. Ultimate safety to personnel is provided by a high flow relief valve set at a higher pressure. This mode is non-regulatory once the high-flow relief valve is opened. It remains open until manually reset. Necessarily the steam system drops rapidly to a mbient conditions introducing a severe thermal transient to the system. Hence the latter is to be avoided if possible.

The low-flow pressure relief might be a turbine by-pass from the steam generator to condenser. A cascade of restrictions could provide the necessary pressure drop resistance and reduce the local erosion problem at each restriction. If the throttled steam temperature to the condenser is too high from a thermal shock viewpoint, a liquid spray injected into this stream can eliminate this problem. A detailed study of this system requires knowledge of the reactor after-heat.

After heat is a problem common to all thermal reactors. Experimental reactors typically have several coolant streams available. During the failure or shutdown of one, another may be put into service to insure the continuous removal of energy. 


\subsubsection{Loss of Secondary Pump, Flow or Flow Sense}

Should some casualty occur whereby the secondary sodium flow rate drops, the normal control action of the primary loop still occurs; i. e. primary and secondary flow still track. The loss of secondary flow develops an error signal at the secondary controller which would drive the secondary pump motor field current to its maximum value. However, if the secondary set point selector sense primary flow rate then the secondary controller will track primary flow for it will be the low signal to the selector. A small gain should be in this sense path otherwise the selector would be actuated under a normal load change. Maximum normal load change is a $10 \%$ variation; therefore, a 1.15 gain in the primary sense path should be satisfactory. Through the speed governor set point override the steam valve control system pressure.

Should flow sense be lost then the signal or lack of signal from the sensor should be down at the bottom end of the calibration range when a lower selection operation is used. Then the primary flow rate will drop to its low value which in turn actuates the secondary selector and drops the secondary flow rate.

If flow is lost in a pipe fracture then the very same mode of action ensues to a loss of sense or pump.

\subsubsection{Loss of Primary Pump, Flow or Flow Sense}

The primary flow rate drops for a loss of primary pump. This signal actuates the secondary pump flow then tracks 1.15 times the primary flow. The reduced signal feedback to the primary controller provides a large error signal which would drive the pump motor field current to its upper limit. However, the reduced set point, secondary flow, prevents this. Also in this mode, the turbine governor override provides pressure control to the system. The very same step-by-step argument for loss of primary sense or pipe fracture follows and the very same mode of action goes into operation.

\subsubsection{Controller Failure}

Controller failure differs from the failures considered in that no means are available to operate the manipulated variable. This is open loop operation. The system has no controlled means of regulation or isolation from disturbances. The safest conditions may be a controlled shutdown.

Sodium flow controllers should fail to a low value. This takes the system down to its shut-off flow rate.

Level controller failure is not quite so critical for a supplementary control exists when the sodium flow controllers track boiler liquid level.

The pressure controller should fail to a low signal. This means no pressure feedback. The system regulation now follows through the feed forward 
control of steam sense to sodium controller set point.

\subsubsection{Loss of Steam Pressure and Flow Sense}

The pressure regulation scheme relies upon a pressure and flow rate measurement of the steam system. If pressure sense fails, the regulator will drive the sodium flows to their upper limit. This could lead to a severe over-pressurization of the boiler. The pressure relief valve provides the ultimate safety. Two remedies may be possible. The pressure signal could be biased to the regulator set point valve so that upon failure no signal or the biased signal ensues. This failure would then be identical to a pressure regulator failure. Under this scheme regulation persists through the feed forward steam flow action.

If the steam sense goes out, then the system persists under the action of the pressure regulator. This mode provides sufficient regulation but lacks the speed of response associated with the feed forward action.

\section{5 Transient Response Under Casualty Control}

Analog studies have shown that controlled adjustment of flows can be achieved in much less time than the characteristic temperature response times of the heat exchangers. Therefore, with respect to the heat exchanger temperature response time, the casualty and normal control systems assure virtually instantaneous tracking of the two sodium flows and the steam and feedwater flows down to $15 \%$ of the rated values. For this reason, the maximum transient variation in temperature at any point in the sodium or steam path is not greatly different from the value predicted by steady-state analysis

These temperature changes are so small, that an accurate computer determination of the actual transients requires very detailed modeling of the system behavior. It was felt that the information which could be gained from such a computer study would not justify the added sophistication required for reasonable accuracy, particularly since the film coefficient dependencies are not accurately known.

An order of magnitude estimate of the characteristic (mean delay) time of response to a flow change for each exchanger is half the exchanger's largest transport time. This time is inversely proportional to the flow rates and is therefore very large at low loads.

The minimum controlled sodium flow rates are $15 \%$ of the rated values. Therefore, should a casualty occur such that one flow drops below this value, the casualty control will not cause the flows to track. Therefore, large variations in system temperatures might occur, but the characteristic time for these variations would be six or more times slower than at rated load. Hence transient thermal diffusion through the tube sheets is much greater than if no casualty control existed in the 100 to $15 \%$ of rated load range. 
At very low flow rates, the prediction of transients is difficult because of the importance of reactor decay heat, axial conductivity in the tubes and liquid sodium, and unusual flow distributions. No attempt is made to treat the low flow problem in this study. 


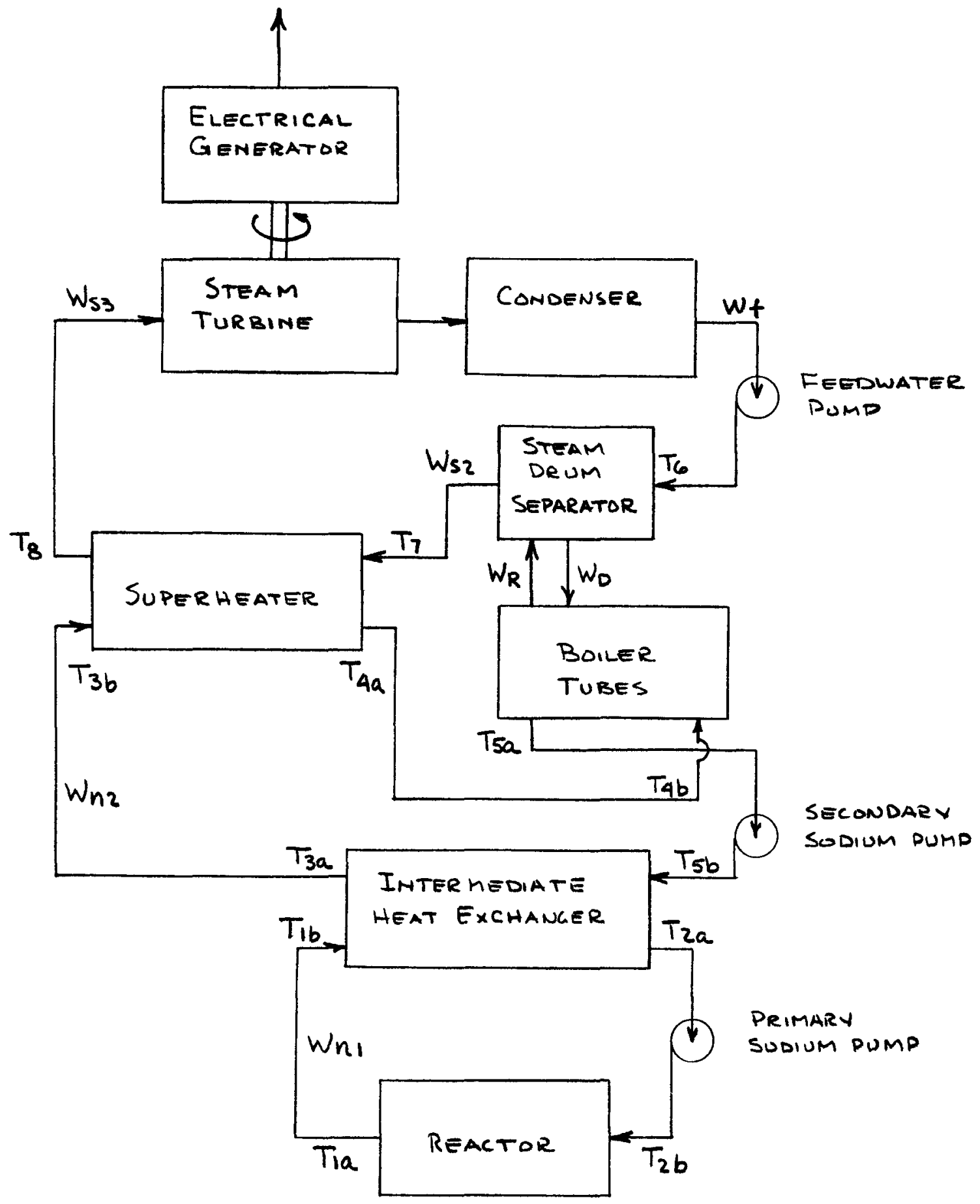

System Schematic Diagram

FIG. 1 


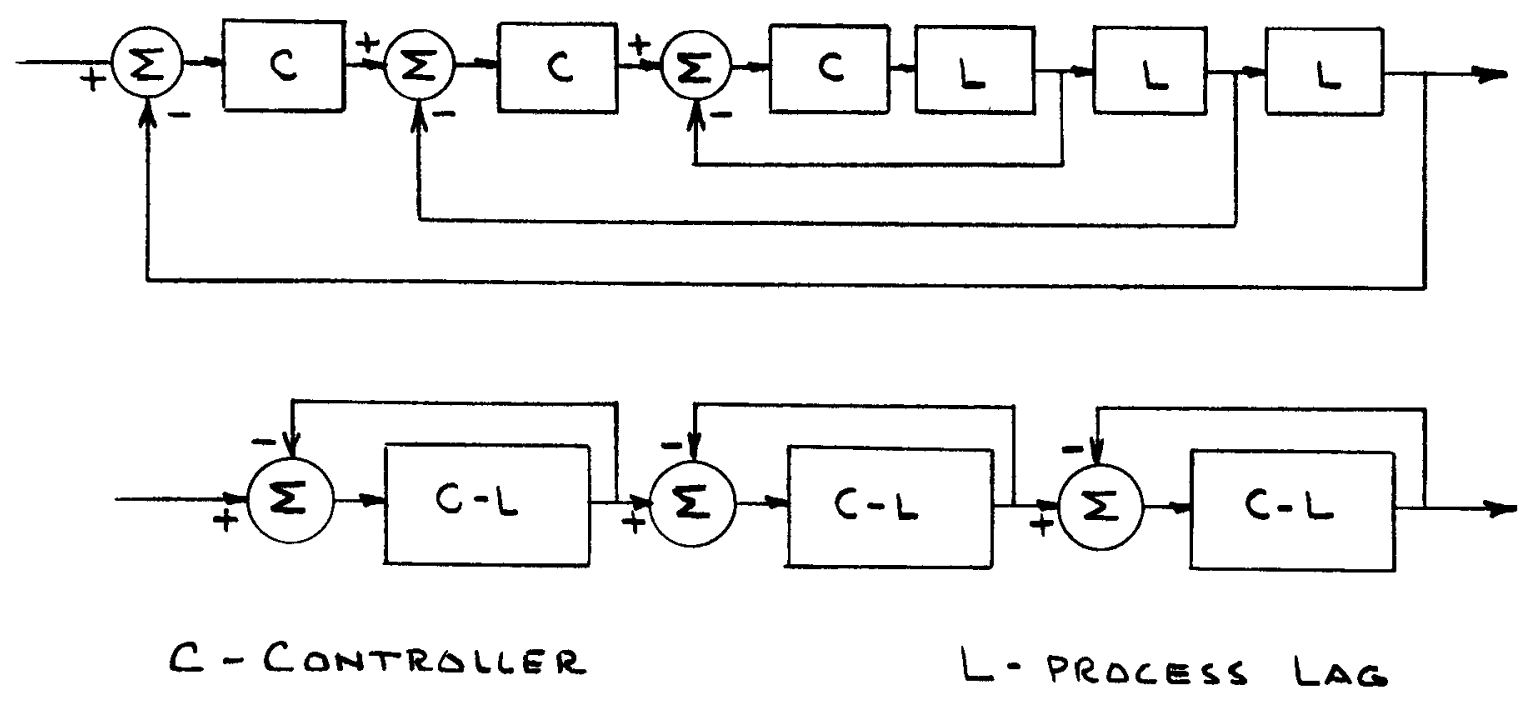

Cascaded Controllers

Fig. 2 . 


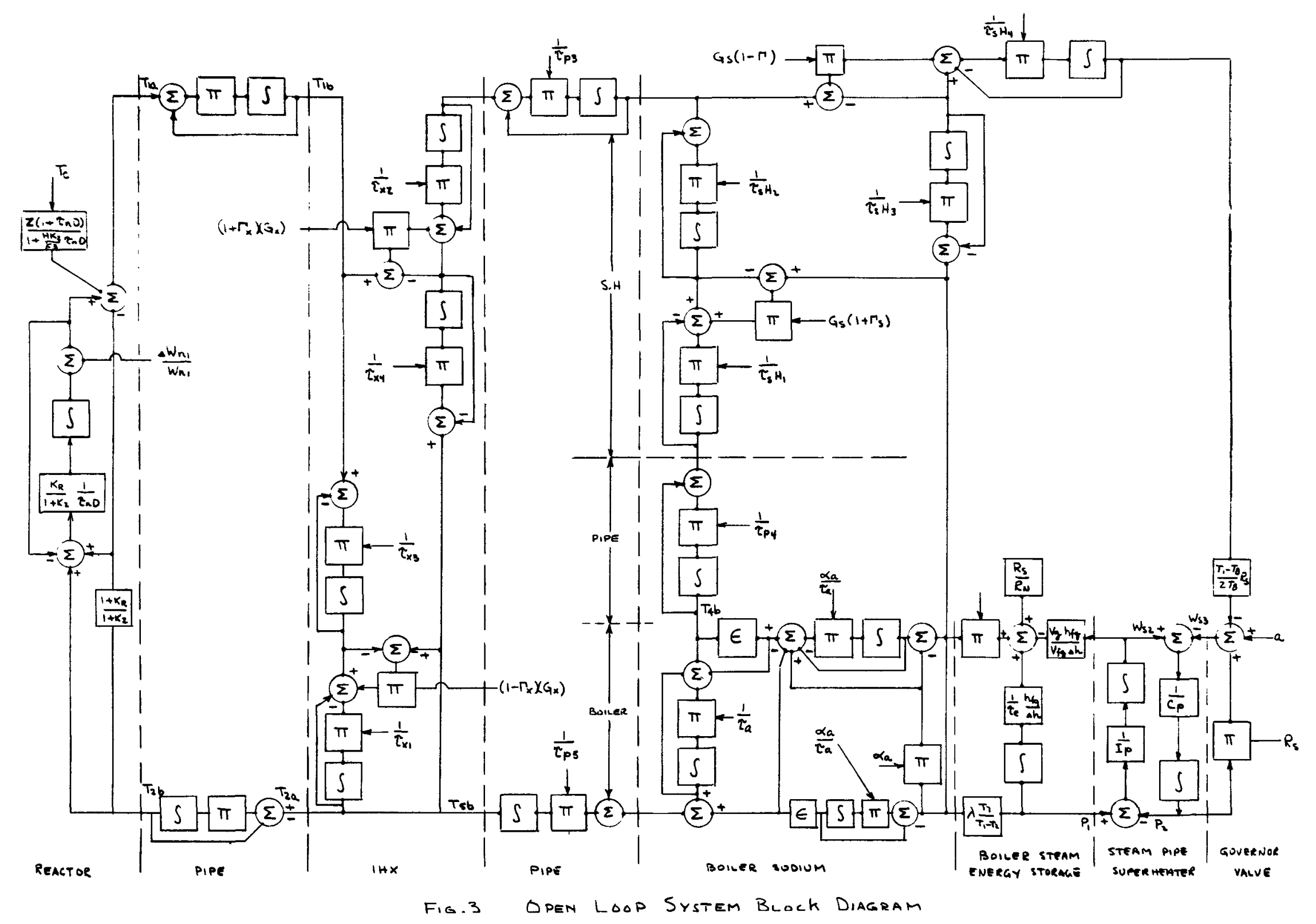




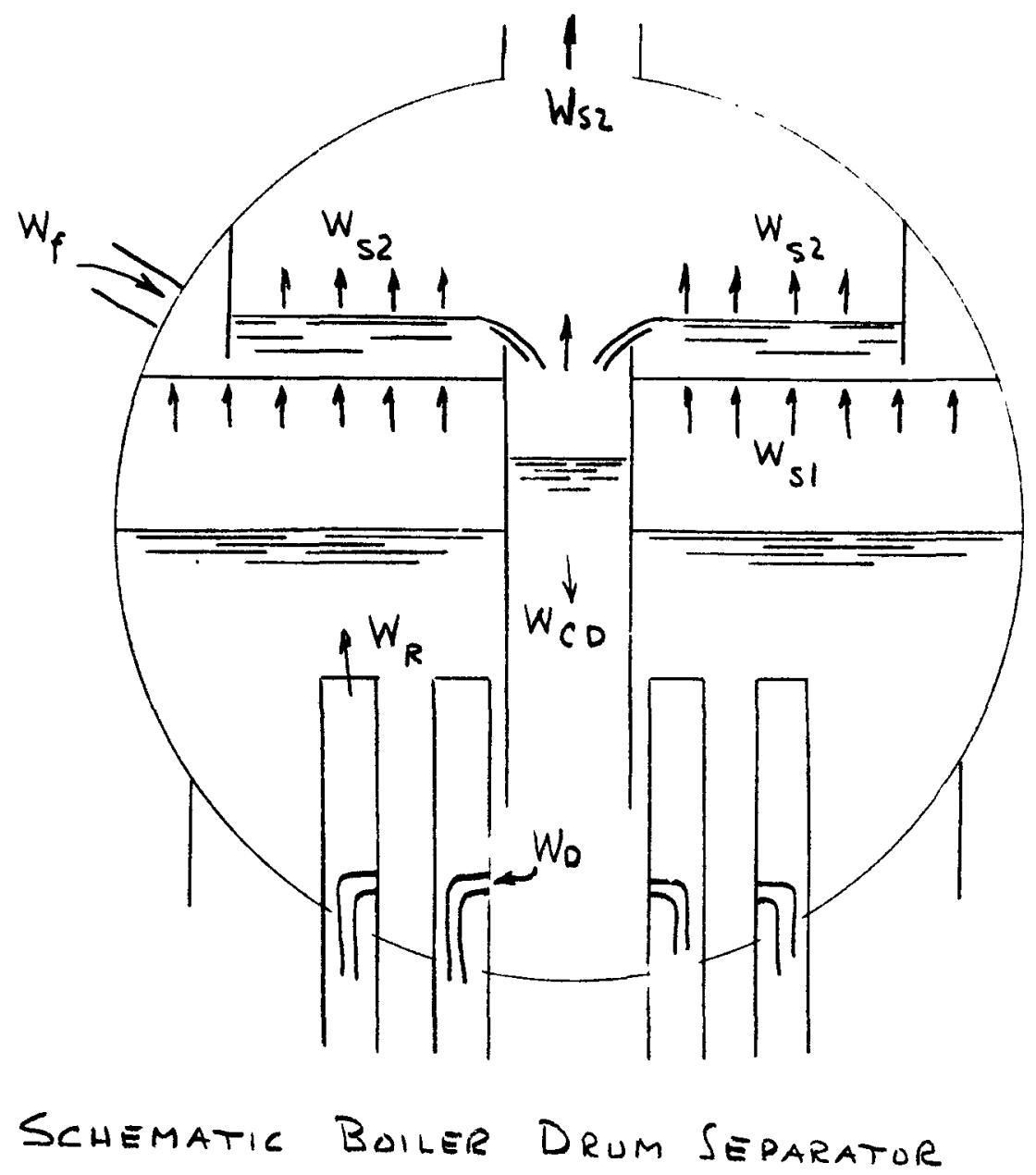

FIG. 4 


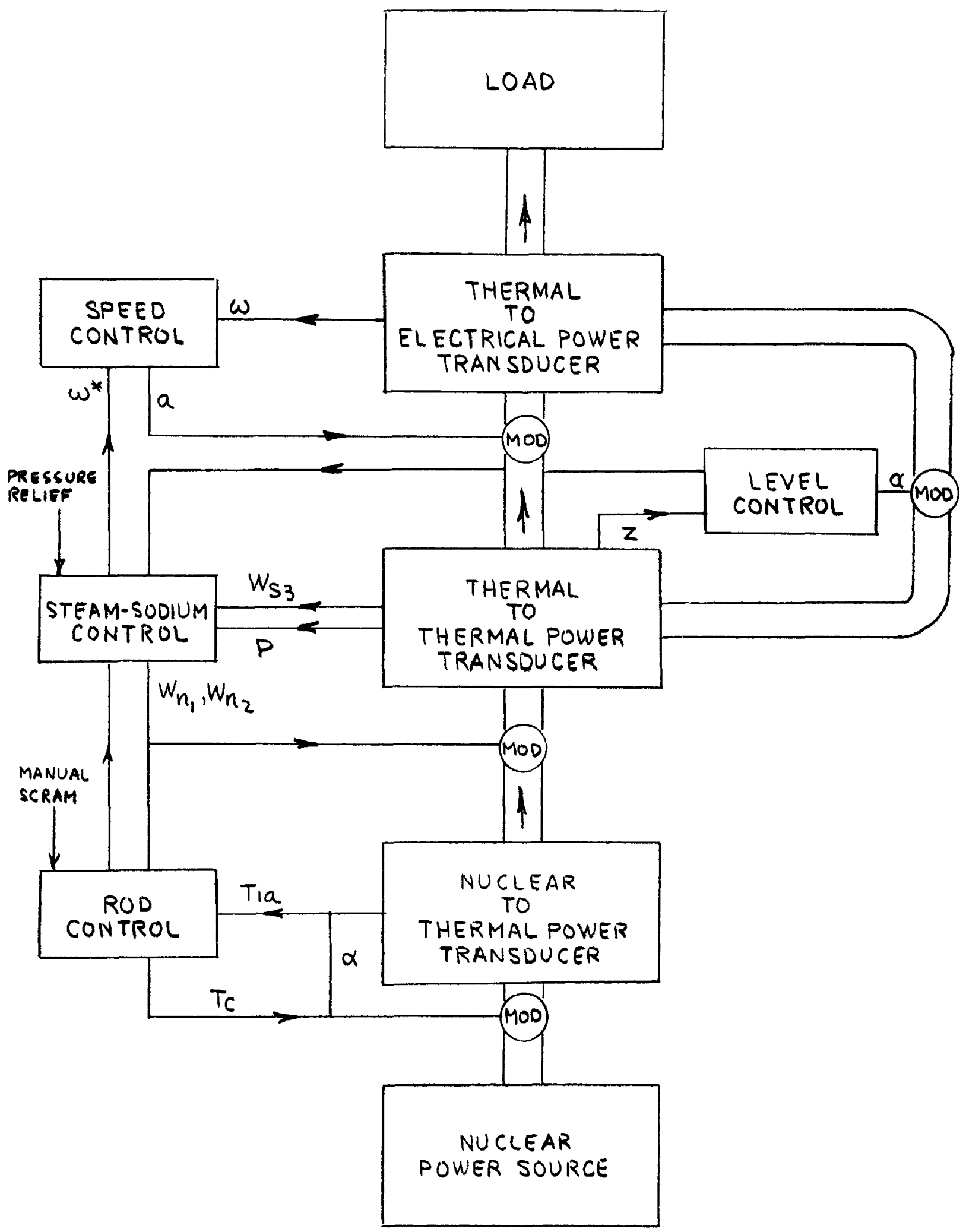

SYSTEM MODULATION CONGEPT AND CONTROL MODES Fig. 5 


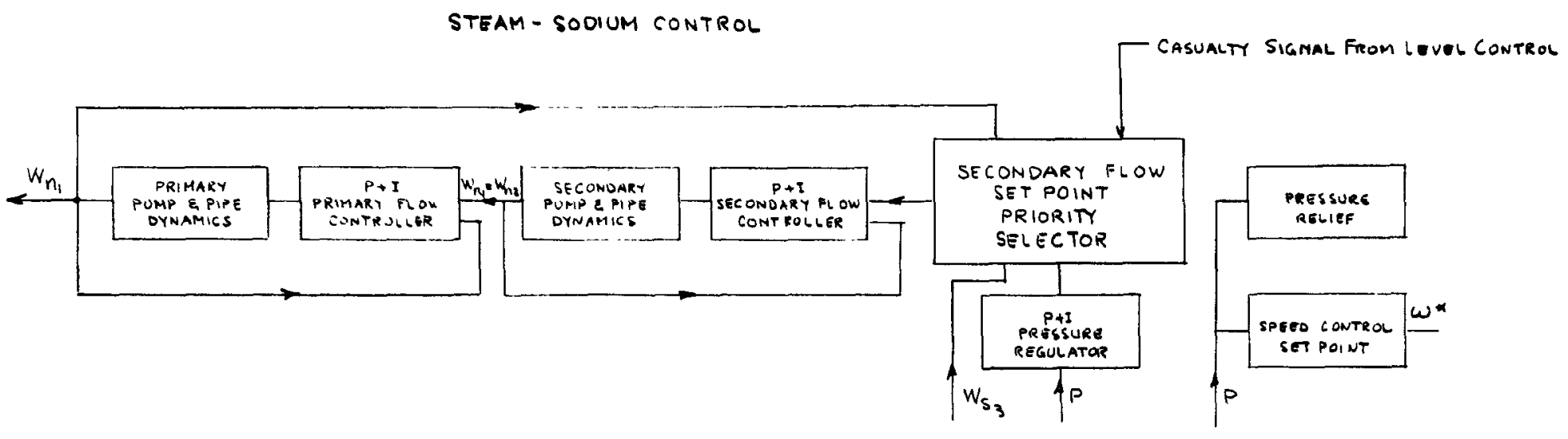

Normal COntrol MODE
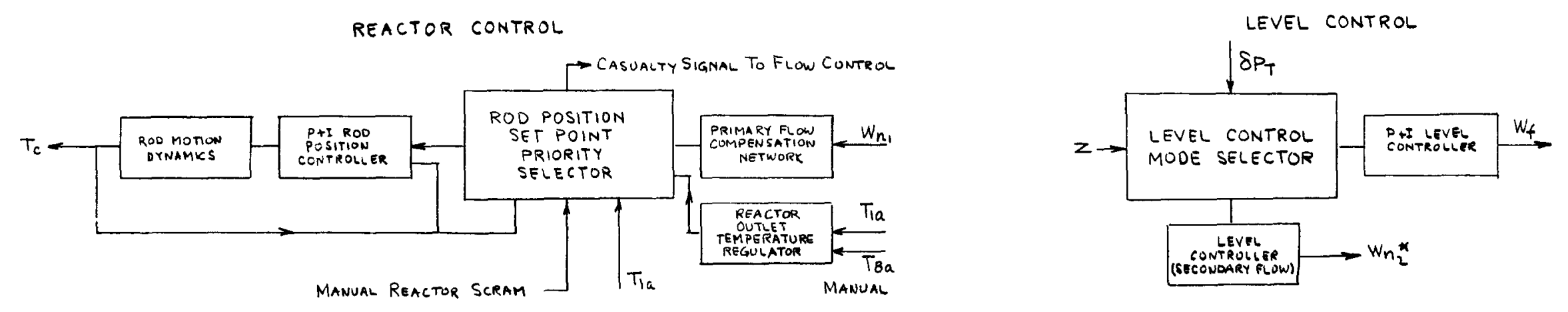

CONTROLLER SYSTEMS

FIG. 6 
Parameter Values for Figure 8

\begin{tabular}{|c|c|c|c|c|c|c|c|}
\hline $\begin{array}{l}\text { Pot. } \\
\text { No. }\end{array}$ & Parameter & $\begin{array}{c}100 \% \\
\text { Load Pt. }\end{array}$ & $\begin{array}{l}20 \% \\
\text { Load Pt. }\end{array}$ & $\begin{array}{l}\text { Pot. } \\
\text { No. }\end{array}$ & Parameter & $\begin{array}{c}100 \% \\
\text { Load Pt. }\end{array}$ & $\begin{array}{l}20 \% \\
\text { Load Pt. }\end{array}$ \\
\hline 1 & $K_{p}$ & & & 19 & $\frac{R_{q}}{B}$ & 1.776 & .3560 \\
\hline 2 & $\frac{1}{\tau_{2}}$ & & & 20 & $\frac{\lambda T_{7}}{T_{1}-T_{2}}$ & .3000 & .2800 \\
\hline 3 & $\frac{K_{p}}{\tau_{2}}$ & & & 21 & $\alpha_{a} \frac{R_{q}}{B}$ & 5.150 & 2.460 \\
\hline 4 & $\frac{1}{\tau_{2}}$ & & & 22 & $\frac{\alpha_{a}}{\tau_{a}}$ & .3950 & .1880 \\
\hline 5 & $\frac{1}{\tau_{\times 2}}$ & .1538 & .0699 & 23 & $\epsilon \frac{a_{a}}{\tau_{a}}$ & .3720 & .1878 \\
\hline 6 & $\frac{1}{2 \bar{R}_{N}}$ & .500 & 2. 500 & 24 & $\frac{1}{\left(1+K_{R}\right) R_{N}}$ & .3750 & 1.875 \\
\hline 7 & $\frac{1}{2}\left(1-\Gamma^{2}\right) \frac{1}{R_{S}}$ & .4482 & 2.118 & 25 & $\frac{K_{R^{-1}}}{1+K_{R}}$ & .2500 & .2500 \\
\hline 8 & $\frac{1}{2}\left(1-\Gamma^{2}\right) \frac{1}{R_{N}}$ & .4482 & 2.224 & 26 & $\epsilon$ & .9430 & .9990 \\
\hline 9 & $\frac{1}{\tau_{x 1}}$ & .1538 & .0699 & 27 & $1-\epsilon$ & .0570 & .0010 \\
\hline 10 & $\frac{1}{\tau p}$ & & & 28 & $\frac{1}{T p 5}$ & .7800 & .1560 \\
\hline 11 & $\frac{\left(T_{1}-T_{8}\right) R_{S}}{2 T_{8}}$ & .0493 & .0455 & 29 & $\frac{1}{\tau_{p 5}}$ & .7800 & .1560 \\
\hline 12 & $R_{\boldsymbol{S}}$ & 1.000 & .2120 & 30 & $\frac{1-G_{x}}{\tau_{x 1}}$ & .0174 & .0030 \\
\hline 13 & $\frac{1}{\tau_{1}}$ & & & 31 & $\frac{G_{x}}{T_{x_{1}}}$ & .1364 & .0669 \\
\hline 14 & $\frac{1}{\text { Te }}$ & .1612 & .1612 & 32 & $\frac{\mathrm{G}_{\mathrm{FN}}}{\tau_{\mathrm{SH}}}$ & .2281 & .0529 \\
\hline 15 & $\frac{1}{2 R_{N}}$ & .5000 & 2.500 & 33 & $\frac{1-G_{S H}(1 \pm 1)}{\tau_{S H_{1}}}$ & . 1797 & .0305 \\
\hline 16 & $\begin{array}{l}\alpha_{a} \\
\tau_{a}\end{array}$ & .3950 & .1880 & 34 & $\frac{\mathrm{G}_{\mathrm{SH}}(1+1)}{\tau_{S H_{1}}}$ & .1289 & .0257 \\
\hline 17 & $\epsilon \frac{\alpha_{a}}{\tau_{a}}$ & .3720 & .1878 & 35 & $\frac{1}{\tau_{S H_{1}}}$ & .3086 & .0562 \\
\hline 18 & $\frac{\alpha_{a}}{\tau_{a}}$ & .3950 & .1880 & 36 & $\frac{1}{\tau_{P_{4}}}$ & 1.008 & .202 \\
\hline
\end{tabular}

FIG. $7(a)$ 
Parameter $V a^{2}$ w for Figure 8

\begin{tabular}{|c|c|c|c|}
\hline $\begin{array}{l}\text { POT. } \\
\text { NO. }\end{array}$ & PARAMETER & $\begin{array}{l}100 \% \\
\text { LOAD PT. }\end{array}$ & $\begin{array}{c}20 \% \\
\text { LOAD PT }\end{array}$ \\
\hline 37 & $\frac{1}{\tau_{P_{4}}}$ & 1.008 & .202 \\
\hline 38 & $\frac{1}{\tau_{S_{2}}}$ & .9250 & .1850 \\
\hline 39 & $\frac{K}{\tau_{S_{2}}}$ & & \\
\hline 41 & $\frac{1}{\tau_{a_{z}}}$ & 420.0 & 49.7 \\
\hline 44 & $\frac{1}{\tau_{a_{z}}}$ & 420.0 & 497.0 \\
\hline 45 & $\frac{1}{\tau_{a_{1}}}$ & 420.0 & 497.0 \\
\hline 46 & $\frac{K}{\tau_{a_{1}}}$ & & \\
\hline 47 & $\frac{1}{\tau_{s_{1}}}$ & 1.800 & .3700 \\
\hline 48 & $\frac{1}{\tau_{s_{1}}}$ & 1.800 & .3700 \\
\hline 49 & $\frac{1}{\tau_{N}}$ & .8130 & .8130 \\
\hline 50 & $\frac{1}{\tau_{N}}$ & .8130 & .8130 \\
\hline 51 & $\frac{2 K_{R}}{\left(1+K_{R}\right) \tau_{N}}$ & 1.016 & 1.016 \\
\hline 52 & \begin{tabular}{c|}
$\mathrm{K}_{R}$ \\
$\left(1+\mathrm{K}_{R}\right) \tau_{N} R_{N}$
\end{tabular} & .5080 & 2.540 \\
\hline 53 & $\frac{K}{\tau_{R_{1}}}$ & & \\
\hline 54 & $\frac{1}{\tau_{R_{I}}}$ & & \\
\hline 55 & $\frac{2 K_{R}}{\left(1+K_{R}\right) \tau_{N}}$ & 1.016 & 1.016 \\
\hline 56 & $\frac{K_{R}}{\left(I \mp K_{R}\right) \tau_{N}}$ & .5080 & $.5080^{\circ}$ \\
\hline 57 & $\frac{1}{2 K_{R} R_{N}}$ & .300 & 1.667 \\
\hline 58 & $\frac{1}{\tau_{R}}$ & & \\
\hline
\end{tabular}

\begin{tabular}{|c|c|c|c|}
\hline $\begin{array}{l}\text { POT. } \\
\text { NO. }\end{array}$ & PARAMETER & $\begin{array}{l}100 \% \\
\text { LOAD PT }\end{array}$ & $\begin{array}{c}20 \% \\
\text { LOAD PT }\end{array}$ \\
\hline 59 & $\frac{1}{2 K_{R} R_{N}}$ & .300 & 1.667 \\
\hline 60 & $\begin{array}{r}2 \mathrm{~K}_{R} \\
1+K_{R} \\
\end{array}$ & 1.250 & 1.250 \\
\hline 61 & $\frac{1}{1+K_{R}}$ & .3750 & .3750 \\
\hline 62 & $\frac{1}{\tau_{p_{1}}}$ & 1.560 & .312 \\
\hline 63 & $\frac{1}{\tau p_{1}}$ & 1.560 & .312 \\
\hline 64 & $\frac{1-G_{x}}{\tau_{x_{1}}}$ & .0174 & .0030 \\
\hline 65 & $\frac{1}{\tau_{x_{1}}}$ & .1538 & .0699 \\
\hline 66 & $\frac{1}{\tau_{p_{2}}}$ & 1.560 & .312 \\
\hline 67 & $\frac{1}{T p_{2}}$ & 1.560 & .312 \\
\hline 68 & $\frac{G_{x}}{T_{x_{2}}}$ & .1364 & .0669 \\
\hline 69 & $\frac{1}{T x_{z}}$ & .1538 & .0699 \\
\hline 70 & $\frac{1}{\tau_{p_{3}}}$ & .7800 & .1560 \\
\hline 71 & $\frac{1}{\tau_{p_{3}}}$ & .7800 & .1560 \\
\hline 72 & $\frac{\mathrm{G}_{\mathbf{S H}}\left(1-\Gamma_{\mathbf{S}}\right)}{\tau_{\mathbf{S H Z}}}$ & .3450 & .0617 \\
\hline 73 & $\frac{1}{\tau_{S H_{2}}}$ & .4237 & .0677 \\
\hline 74 & $\frac{1-G_{S H}\left(1-I_{S}\right)}{\tau_{S H 2}}$ & .0787 & .0060 \\
\hline 75 & $\frac{\mathrm{G}_{\mathrm{FS}}}{\tau_{\mathrm{SH}}}$ & .1822 & .0258 \\
\hline 76 & $\frac{R_{q}}{R_{N}}$ & 1.000 & 1.059 \\
\hline 78 & $\frac{\left(\alpha_{a}\right)^{2}}{\tau_{a}}$ & 1.144 & 1.297 \\
\hline
\end{tabular}

FIG $7(b)$ 
PRESSURE CONTROL DIAGRAM BERKELEY $\| O O$ EASE COMPUTER

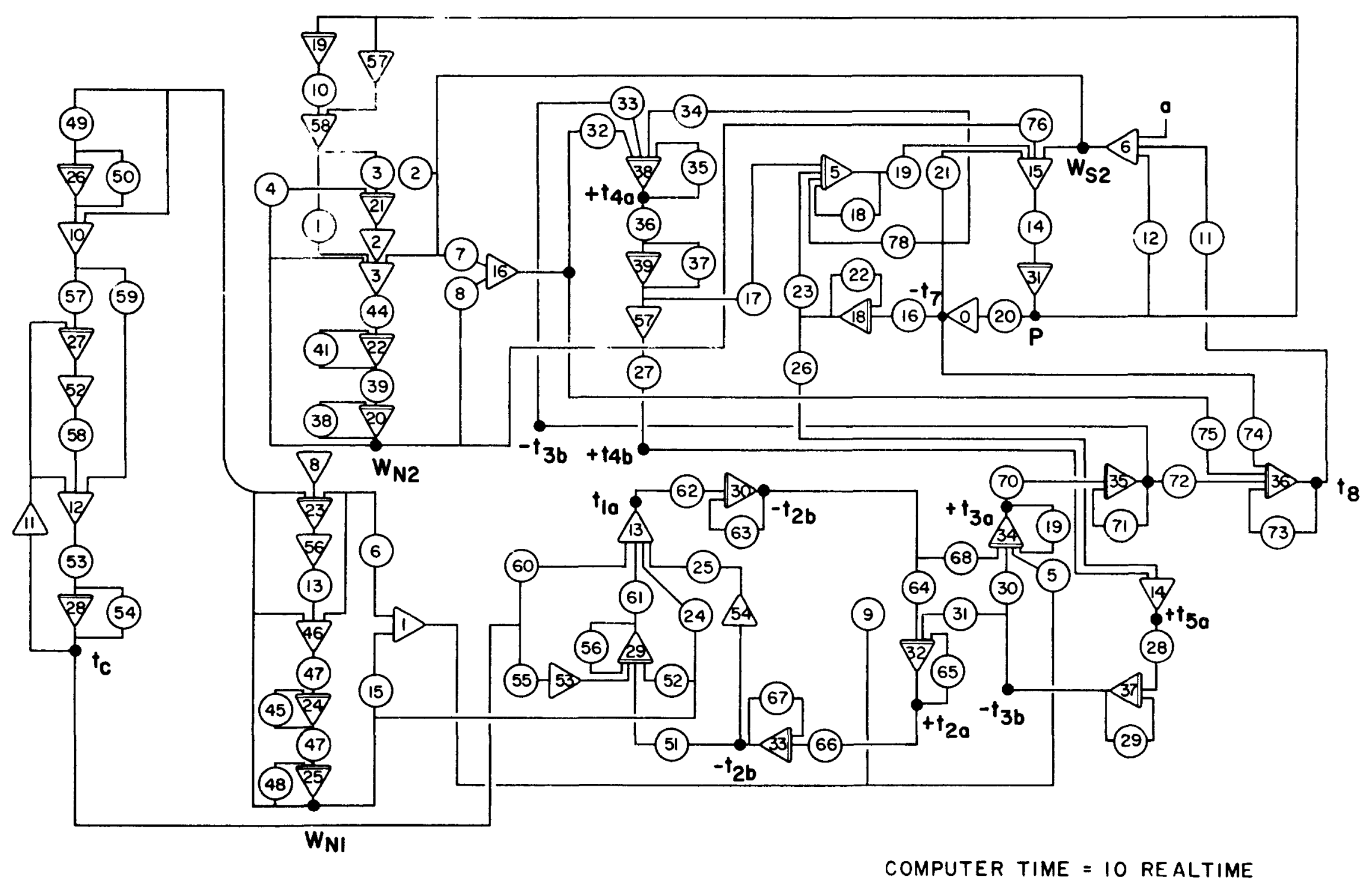

FIG. 8 